\title{
Subcentres and Satellite Cities: Tokyo's 20th Century Experience of Planned Polycentrism
}

\author{
ANDRÉ SORENSEN \\ Department of Urban Engineering, University of Tokyo, Hasamagaoka 3-25-3, Sanda-shi, \\ Hyogo-ken, Japan 669-1545
}

\begin{abstract}
This paper examines the role of subcentres and satellite cities in the patterns of growth of the Tokyo Metropolitan Area, first outlining the development of metropolitan planning ideas for the Tokyo region from the 1920s to the 1990s, and then examining empirical evidence on patterns of population and employment change that occurred from 1970 to 1995 to determine the degree to which a polycentric pattern of growth has emerged. Japanese planners initially adopted European greenbelt/satellite city schemes uncritically, and then gradually adapted them to circumstances in Japan, eliminating the greenbelt concept along the way. Metropolitan plans have since the 1970s instead proposed the development of a multi-polar metropolitan region as a way of reducing travel needs and distances while eliminating the need to prevent development in intervening areas. The data on patterns of change of population and employment suggests that there has indeed been a considerable tendency towards polycentric development in the Tokyo region, although not only in the planned subcentres, and even though the core area has maintained or increased its dominance as an employment centre. The implications of these findings are then explored.
\end{abstract}

\section{Introduction}

One of the dominant issues of 20th-century planning was the question, already firmly on the agenda at the end of the 19th century, of what to do about the growth of very large metropolitan regions. A range of arguments were made about the need to control the overall size and form of the largest cities as many observers became convinced that the problems being created by the unprecedented physical expansion of the largest cities were qualitatively different from earlier urban problems, and required new planning powers. The main evils arising from overgrown cities were seen as congested transport systems, particularly roads; rising land costs; longer travel-to-work times which quite apart from the time costs to individuals would result in productivity losses because of worker fatigue; decreased access to open space and the countryside; increased need for costly investments in new infrastructure; increasing pollution of air and water; worsening health problems; and even increasing moral degeneracy and crime (Howard, (1898) 1985; Mumford, 1940; Saarinen, 1943; Self, 1961; Blumenfeld, 1967).

Perhaps the most widely agreed solution to those problems was the promotion of multiple nodes of concentrated activity within the metropolitan region, commonly referred to as subcentres or satellite cities. Subcentres are 
concentrations of employment and/or commercial activities distinct from the main CBD but within the continuously built-up area, and are often associated with major transportation transfer points such as rail, subway and bus interchanges. Satellite cities on the other hand, are usually conceived as new developments or major expansions to existing settlements that are separated from the metropolitan core by belts of rural land. Planners argued that restrictions should be placed on central growth, and the development of separate centres within the metropolitan region encouraged. The Greater London Plan of 1944 prepared by Patrick Abercrombie was possibly the most influential such plan. It assumed that London was too big and too densely populated in central areas, that people needed access to countryside and that problems of housing, transport, congestion and pollution could be solved through decentralization. London would therefore be ringed around with a green belt to prevent further physical growth, and the existing population of overcrowded central areas would be decanted into new and expanded towns outside the greenbelt (Cherry, 1988 , p. 126). The ideas developed in wartime Britain quickly became the dominant paradigm for understanding metropolitan growth and its management throughout the world, although the actual ability to implement such programmes varied considerably in practice.

Although the 1970s and 1980s saw increased questioning about the practicality and possible adverse effects of metropolitan planning strategies (e.g. Hall et al., 1973), in the 1990s questions of urban form at the metropolitan region level re-emerged as important issues as planners and planning theorists began to address issues of urban environmental sustainability. It was argued that the energy demands of cities, particularly for transport, but also for space heating and cooling are significantly influenced by overall patterns of urban form, and these two categories account for over half of delivered energy needs in the UK (Owens, 1991). It was also suggested that higher density forms of urban development allow the efficient operation of public transport systems, can cut down on the overall distances travelled, and make walking and cycling viable for a significant proportion of all trips. All of these would tend to reduce the amount of private automobile travel, which is the most wasteful of energy, is a prime cause of congestion, air and noise pollution and is a key source of danger for city residents, particularly children (Sherlock, 1991; Fowler, 1992). These arguments were supported by the research of Newman \& Kenworthy (1989b) who demonstrated that cities with higher densities have consistently lower rates of gasoline consumption. Proponents of higher densities also argued that they allow a higher quality of life by ensuring the continued vitality and culturally rich life of a healthy city (Commission of the European Communities (CEC), 1990), and that "Retaining 'urban' densities of housing would ensure the survival of local facilities like shops, pubs, primary schools, doctors' surgeries and bus-stops within walking distance of everyone's front door" (Elkin et al., 1991, p. 17).

Although it is not yet agreed which metropolitan form will prove most energy efficient, the most widely agreed suggestion is that an urban form similar to the 'decentralized concentration' attempted in Denmark and Sweden might be the most promising approach (Rickaby, 1987; Elkin et al., 1991; Owens, 1991; Breheny \& Rookwood, 1993). The development of nodes of concentrated mixed use within the urban fabric would allow most needs to be satisfied within local areas, reducing the necessity for long trips to the city centre, and the 
nodes would be linked by public transit for longer trips. It is suggested that this model could allow high levels of living standards and mobility, while reducing overall automobile use. This concept, of course is remarkably similar to, and borrows heavily from, the subcentre/satellite ideas of the first half of the century.

There are two important general problems with these proposals for energy efficient urban development. The first is that as Hall (1997, pp. 215-216) has argued, much of the research on efficient urban form has remained highly theoretical and has yet to yield persuasive recommendations on a 'best' overall metropolitan urban form. A vigorous debate continues over the environmental implications of metropolitan growth patterns, with some arguing that metropolitan dispersal may not be a problem if jobs and housing disperse together, leading to shorter commutes (Gordon \& Richardson, 1990, 1995), while others contend that such dispersal is problematic primarily because it leads to greater dependency on automobiles for transport (Cervero, 1989; Newman \& Kenworthy, 1989a; Barton, 1992). The second problem is equally serious and relates to the possibility of achieving an ideal urban form if one were agreed. Breheny (1995), for example has questioned whether the creation of more compact cities and increasing densities is actually achievable. He argues that this goal may be unrealistic because it will mean a radical reversal from long standing trends towards increasing dispersal of population. In addition, as Cherry (1982, p. 148) pointed out, in Western countries with market economies public sector land planning policies have had remarkably little impact on macro-scale metropolitan growth patterns. This is true both in the case of countries such as Britain, which has developed an elaborate and relatively strict land development control system, and countries such as the United States or Japan where land development control has been relatively looser.

In this context, a strategy of promoting subcentres of 'concentrated mixed use' can be seen as a sort of pragmatic compromise to the difficulties of shaping overall patterns of urban growth. In existing large metropolitan areas, or in metropolitan areas where the control of overall patterns of growth is difficult or impossible for whatever reason, it may be possible to encourage the development of subcentres within the urban fabric. These subcentres can potentially achieve many of the goals of more ambitious metropolitan structure plans while avoiding the need to shape overall patterns of growth. The concentration of employment opportunities and high level services within these nodes would reduce the necessity for long trips to the city centre and would lead to more sustainable patterns of metropolitan development over the longer term by facilitating the use of public transit and district 'cogeneration' heating and electricity generating technologies. Such an approach does not, of course, preserve the tracts of 'field, hedgerow, and woodland' so valued by early planning advocates in the same way that a satellite city/greenbelt scheme can, but neither does it require the same degree of intervention. Subcentres can be encouraged by primarily positive measures such as the provision of transport infrastructure, public facilities and zoning bonuses rather than requiring strong restrictive regulatory measures such as building prohibitions in greenbelts. Such reasoning has prompted a range of recent research on the role of polycentric development in a number of metropolitan regions such as San Francisco (Cervero \& Wu, 1997), Chicago (McDonald \& Prather, 1994), and Los Angeles (Gordon et al., 1986). 
Tokyo is an important example of a city that has developed a strong set of metropolitan subcentres of which Shibuya, Shinjuku and Ikebukuro on the Yamanote loop rail line are the most famous. Proposals to encourage a number of satellite cities to absorb growth in the Tokyo Metropolitan Region have also been prominent in metropolitan planning strategies in the post-war period. A large number of satellite cities have been designated, and some built, such as Tsukuba, Tama, Kohoku and Chiba new towns, and also many new subcentres including Hachioji, Shin Yokohama and Omiya, and large new regional employment centres such as Chiba's Makuhari Messe, Yokohama's Minato Mirai and the new Tokyo Coastal Subcentre (see Figures 4 and 5).

Given Tokyo's unquestioned position as one of the premier world cities, normally ranked alongside London and New York as one of the top three such (e.g. Sassen, 1991), and the fact that it is one of the largest urban areas in the world, and easily the largest in the developed countries, one would expect that the role of subcentres and satellites in Tokyo's metropolitan growth would have been well researched. Strangely, however, there has been little detailed examination of how subcentre/satellite policies have evolved in Tokyo, or what their impacts have been. This paper outlines the evolution of such policies in the Tokyo case, and examines their impacts on patterns of metropolitan development. The next section describes the evolution of planning policies designed to promote polycentric metropolitan development in the Tokyo metropolitan area, and the following section examines Tokyo's patterns of population and employment growth in order to evaluate the impacts of those plans. A concluding section draws out the most important implications suggested by the Tokyo case.

\section{The Evolution of Nodal Development Strategies in Tokyo}

Throughout the 20th century city planners in both the central government and the Tokyo metropolitan government struggled with the rapid growth of the capital. At the time of the first modern census in 1920 the City of Tokyo already had a population of 3.3 million. Rapid industrialization during the First World War had combined with the increasing mobility of the workforce provided by expansion of the streetcar and rail systems to create conditions of rapid suburban growth. Growth pressures in suburban areas were further greatly increased by the Great Kanto Earthquake of 1923, which at a stroke destroyed over $60 \%$ of the existing built up area, and encouraged a sudden increase in population in new suburban districts. The earthquake also greatly set back city planning in the Tokyo region, as not only were the newly prepared city plans of Tokyo and its suburban districts consumed in the fire which destroyed city hall, but for the next seven years until its completion in 1930 all available resources were put into the Imperial Capital Reconstruction Project. It was thus only in the early 1930s that serious efforts were once again initiated to deal with metropolitan structure issues. By that time the main subcentres, Shibuya, Shinjuku and Ikebukuro, had already developed spontaneously before any official efforts were made to encourage their formation, as a result of the structure of the Tokyo area railway system.

At the end of the 19th century when the Japanese national railway system was first being built it was radially centred on Tokyo. ${ }^{1}$ The Tokaido line was built south and west from Tokyo to Osaka, the Tohoku line ran north from Tokyo to Tohoku, and the Chuo line ran due west to the mountains near Mt Fuji. These 


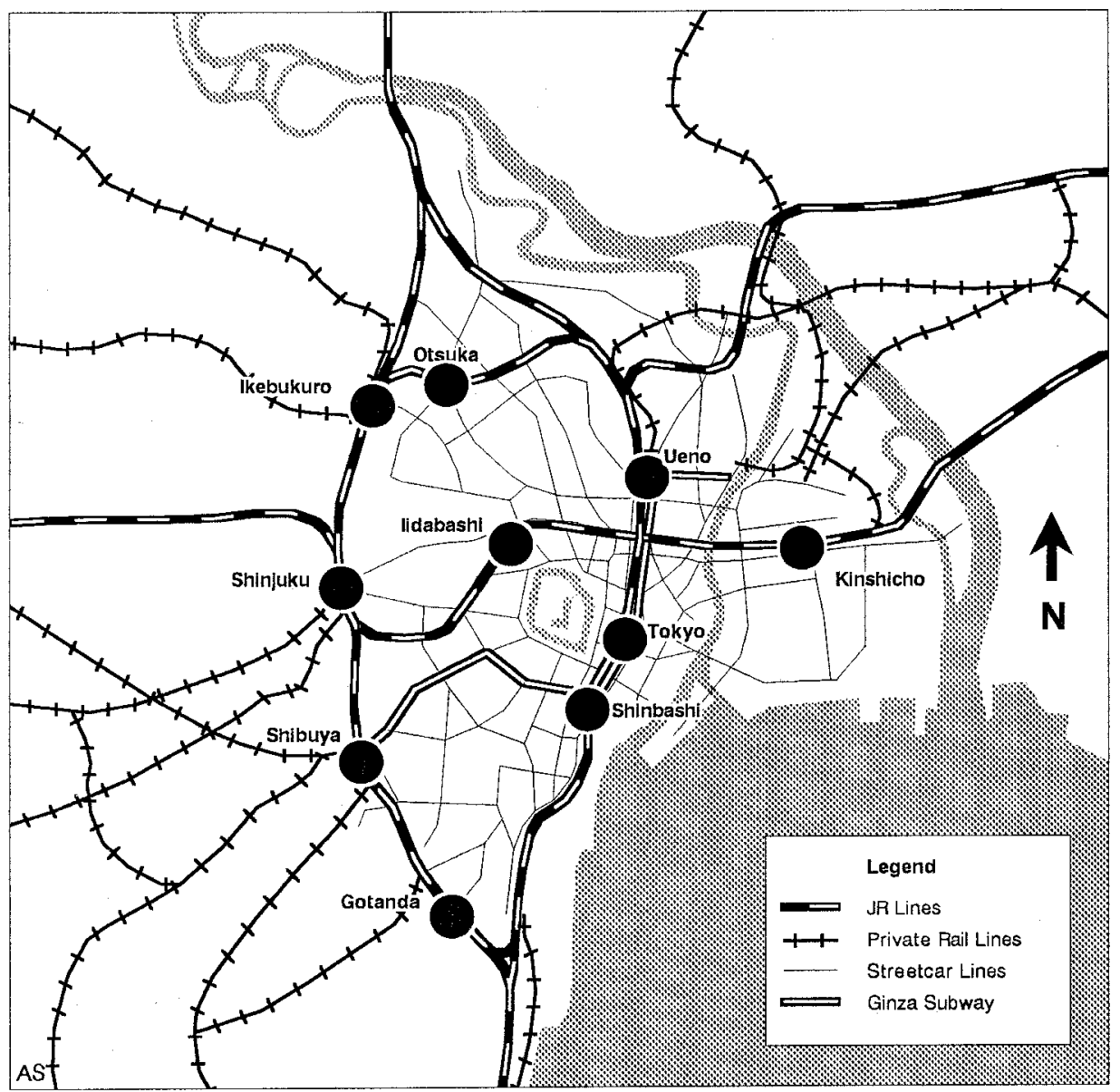

Figure 1. Central Tokyo rail system and main stations in 1930.

lines initially each had their own terminus in the central part of the city, at Shimbashi, Ueno, and Iidabashi respectively (see Figure 1). Just before the turn of the century the Yamanote loop line was built to the west of the then built up area so that freight trains, particularly those carrying silk, Japan's main international export, from central Honshu to the port at Yokohama, could run straight through to the port without unloading in the city. In the final phase of the Tokyo City Improvement Project completed in 1919, the loop was joined on the east side by making a connection through the urban core from Ueno to Shimbashi and Tokyo Station was completed in 1915 to serve as the new central station. The building of the new central station solidified the status of the Marunouchi to Ginza area as the capital's CBD. In the 1920s a new train service, the now famous Yamanote Line, was established to circle the loop. This structure created natural growth points at the intersections of the main radials with the peripheral loop.

A second factor contributing to the establishment of the subcentres was the purchase of the privately built Tokyo streetcar system in 1911 by the Tokyo municipal government. The streetcar system by this time formed a comprehen- 
sive network within the Yamanote loop, with over $190 \mathrm{~km}$ of lines. As the Japan National Rail (JNR) system had been nationalized in 1906, and the streetcar system was now municipally owned, it was simple financial logic that prompted the government to ban privately owned suburban railways from extending their lines to within the Yamanote loop line. This protected at one stroke the revenues of the commuter services of JNR, and the streetcar services within the loop, and meant that the private suburban rail lines had to establish their terminals along the Yamanote line. The rapid suburban expansion from the First World War to the mid-1930s combined with the investment incentives of the central government (Yamamoto, 1993) to encourage the proliferation of private commuter railways which spread radially out from their termini at the main nodes along the Yamanote loop. As the best and most extensive areas of land for suburban development was in the upland plateau to the west of the city, that area developed first and fastest. The three main subcentres of Shinjuku, Shibuya and Ikebukuro thus developed along the west side of the loop where the private lines terminated and commuters had to switch to either JR trains or streetcars to reach the centre. Entertainment and restaurant districts developed in these subcentres to serve those changing trains on the way home, and later branch stores of the main downtown department stores and the major terminal department stores built by the private train companies appeared (Honjo, 1978, p. 148). The initial development of the subcentres was thus largely a product of the inherent advantages of their location at the point where commuters changed travel mode.

During the same period the development of satellite communities in the rural areas around Tokyo was greatly advanced by the same private railway companies, much of whose profits derived from speculative land development ventures along their lines. The first of these developments, Den'en Toshi (Garden City), was inspired by the British garden cities movement, although as Watanabe (1980) argues, little more than the name was really borrowed, as the towns so developed were primarily suburban real estate speculations which had neither the social ownership aspects of Letchworth, nor any semblance of independence from Tokyo where their residents worked. The model proved popular, however, and during the 1930s a considerable number of railway suburbs and university campus towns were built in open countryside within about $30 \mathrm{~km}$ from central Tokyo.

Private sector development both of subcentres and of satellite towns thus occurred considerably in advance of government plans, whose efforts only started to take shape in the 1930s, after the earthquake reconstruction works were completed. Early Japanese metropolitan structure planning was strongly influenced by European ideas. Several Japanese planners, including Ishikawa Hideaki who as head of the Tokyo City Planning Department was responsible for the post-war reconstruction plans for Tokyo, had attended the influential 1924 Amsterdam International City Planning Conference, where a central topic of debate was the issue of planning the metropolis, and a highly influential model was that of the core city ringed by a green belt and surrounded by satellites linked by a radial and loop rail system. Ishida (1987, p. 183) argues that the metropolitan structure model presented to the conference by the German planner Paul Wolf was the model for the Kanto Region Metropolitan Structure Plan proposed by the Tokyo Area City Planning Committee of the Home Ministry in 1940 and reproduced as Figure 2. 


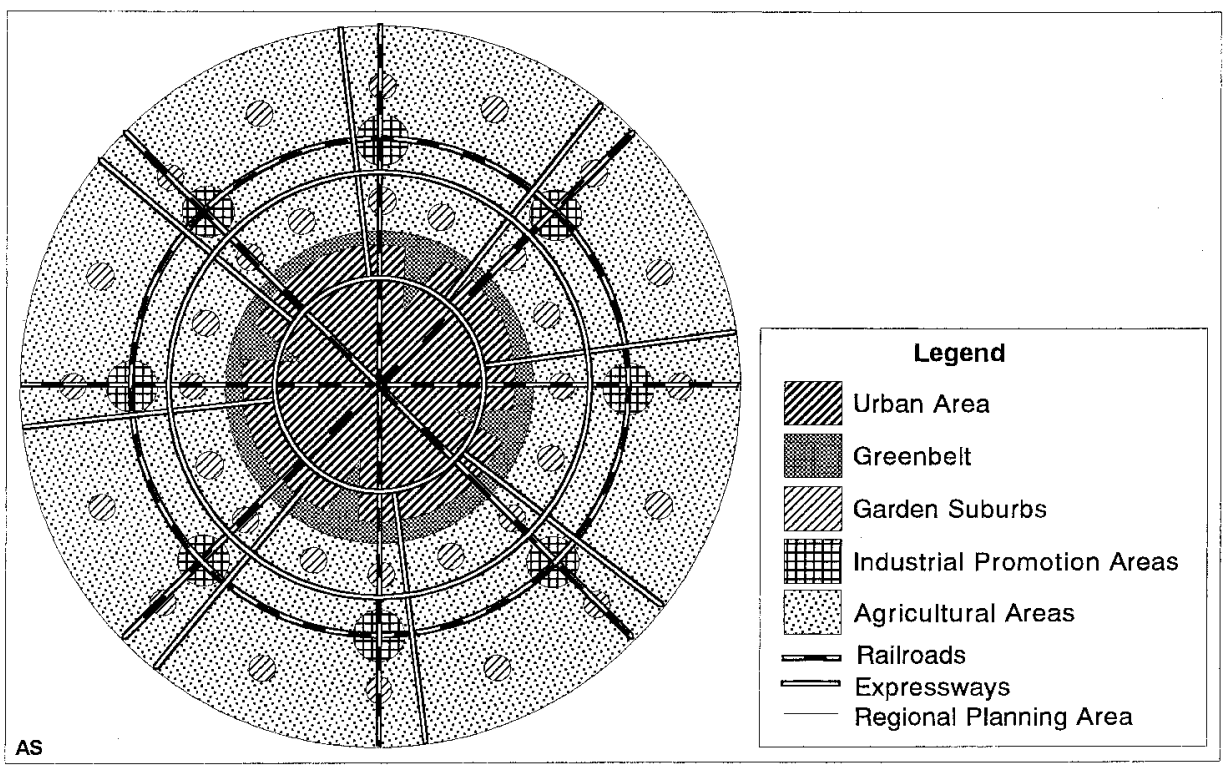

Figure 2. Kanto region Metropolitan structure plan, 1940. Source: Tokyo Metropolitan Government, 1989.

This model of metropolitan structure is also, of course, very similar to Howard's earlier 'Social City' scheme (Howard (1898) 1985 frontispiece), with which the Japanese were almost certainly familiar, as Howard's ideas were well known among planners in Japan, and Home Ministry bureaucrats had in 1907 published a book titled Den'en Toshi (Garden City) introducing Howard's ideas and describing Britain's Garden City Association and Letchworth. The model has been adapted to the Japanese context in several significant aspects, however. The 'garden suburbs' in the Kanto plan are the numerous small settlements scattered throughout the agricultural hinterland of the metropolis. These correspond, it seems safe to assume, to the garden suburbs already being built by the private railway companies. The key locations at the intersections of the radial rail lines with the circumferential line outside the greenbelt are reserved in the

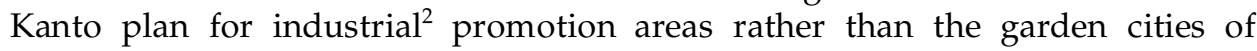
Howard's plan. The priority given to industrial development reflects the timing of the release of the plan in 1940, when Japan was already mobilized for total war, and the development of munitions industries was the top national priority. Several such 'industrial promotion areas' and 'military cities' (gunto toshi) were actually built during the war as a way of dispersing over-concentrated munitions plants from central Tokyo (Ishizuka \& Ishida, 1988, p. 25).

Preparations for war also aided the implementation of a greenbelt plan that had been in preparation since the formation of the Tokyo Regional Green Space Council in 1932. Their proposals were made public in 1939, and included an extensive greenbelt of $13730 \mathrm{ha}, 40$ large parks totalling $1695 \mathrm{ha}$, and 591 small parks totalling 674 ha (Ishizuka \& Ishida, 1988, p. 52). There was neither budget nor land acquisition mechanism adequate to carry out the plan, however, until 
the 1940 revision of the City Planning Law which included air defence as a goal of city planning, and defined green spaces as public facilities, thus making expropriation of land for the greenbelts and parks legally permissible. In this way a considerable area of land for greenbelts was bought, totalling some 646 ha, while much of remainder of the planned greenbelt area was simply designated as Air Defence Open Space and was used for antiaircraft batteries and fighter interceptor bases. After the war the areas which had been purchased were eventually turned into some of Tokyo's larger metropolitan parks, while the rest of the open spaces were quickly engulfed in urbanization (Ishizuka \& Ishida, 1988, p. 23).

The other significant pre-war efforts to plan for subcentres were the elaborate redevelopment plans of the 1930s to rationalize the links between JR stations, private rail stations, streetcars, buses and planned subway lines at the station areas of Shibuya and Shinjuku. To be carried out through land readjustment projects (see Sorensen, 1999; Sorensen, 2000b) and 'excess condemnation'-a Japanese version of Haussmann's urban redevelopment financing methodthese projects were left unfinished as the deepening of war against China and the launch of the Pacific War saw the abandonment of all but strictly military projects.

The subcentre redevelopment projects were a top priority of the post-war War Damage Reconstruction Plan (Sensai Fukō Keikaku) begun in 1946, and the earlier redevelopment plans were dusted off and incorporated into the ambitious plans for the restructuring of the capital. In the event several station areas including Shinjuku, Shibuya, Ikebukuro, Gotanda and Otsuka along the Yamanote loop, and Kinshicho on the Sobu line were among the only parts of the post-war reconstruction plans for Tokyo that were completed, as the redevelopment projects involved large scale Land Readjustment projects which required extensive land expropriation and purchase and aroused strong opposition movements. In the difficult financial climate of the occupation years city planning also suffered from shortages of funds, and at the time the plan was wound up in 1959 only 1380 ha (6.8\%) of Tokyo's original planned area of over 20000 ha had been carried out (Ishida, 1987, p. 231). The impact on the subcentres was important, however, and their basic road and public space structure today was established by those post-war projects.

Planning for the future structure of the capital region began again in the 1950s with the beginnings of economic revival and renewed growth of urban population. In 1951 a National Capital Construction Committee was established which proposed a scheme for satellite town building in 1953, published a concept plan for the capital region in 1956 and drafted the National Capital Region Development Plan (NCRDP) which was approved in 1958. This plan, shown in Figure 3, followed closely the ideas of Abercrombie's plans for London, and also reflects the thinking of the earlier 1940 Kanto region plan. The first NCRDP announced in 1958 also designated Shinjuku, Shibuya and Ikebukuro as subcentres designed to relieve growth pressure on the CBD area.

As shown in Figure 3 the first Capital Region Improvement Plan of 1958 designated a broad greenbelt around the existing built-up area of Tokyo, in emulation of Abercrombie's Greater London Plan (Hanayama, 1986, p. 26). Controls were placed on the location or expansion of industries and universities within the existing 'Built up Area', with development to be channelled to satellite towns beyond the greenbelt. The greenbelt was to act as a cordon 

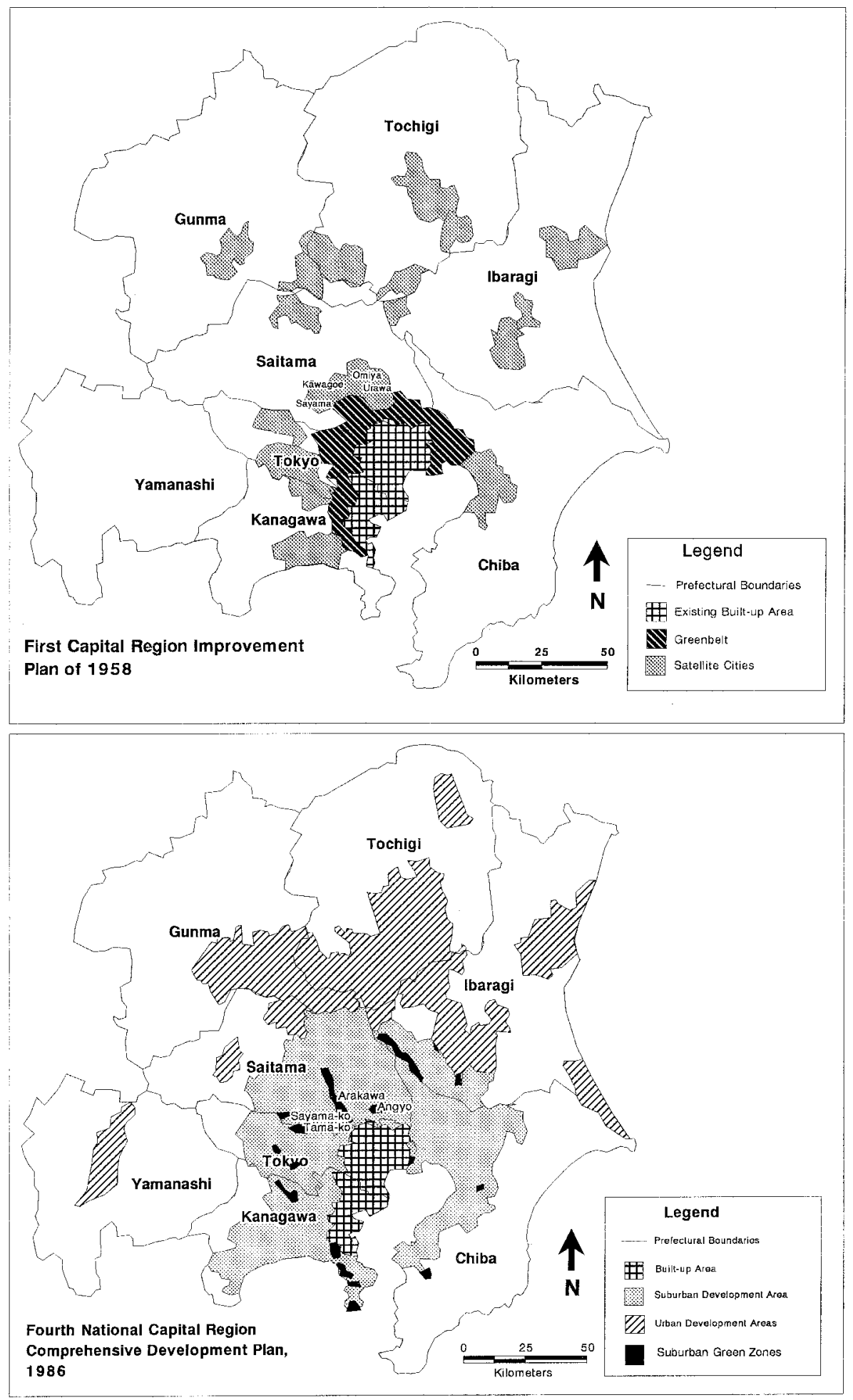

Figure 3. The first capital region improvement plan of 1958, and the Fourth NCRDP of 1986. 
sanitaire around the existing built-up area and maintain a clear separation between Tokyo and its suburban satellites (Alden, 1984, p. 72). The greenbelt was, however, overwhelmed by a combination of greater than expected economic and metropolitan growth, and active local opposition to its implementation. A recent study of the failure of the first Capital Region Improvement Plan to control actual patterns of growth suggests that the lack of concrete legal measures to enforce provisions of the plans, and the fact that the local governments affected were pursuing contrary pro-growth policies were the key factors in undermining its effectiveness (Kurosawa et al., 1996). Through a combination of political lobbying and landowner strategies of actively subdividing and selling farmland in the proposed greenbelt area, forces opposed to the plan were able to ensure that its greenbelt provision would be unenforceable.

In response the Second National Capital Region Development Plan (NCRDP) of 1968 eliminated the greenbelt and designated the whole area outside the existing built-up area and within a $50 \mathrm{~km}$ radius of Tokyo Station a Suburban Development Area while retaining the satellite cities in the northern part of the region. This second approach to planning the metropolitan structure has continued to form the basic strategy of the Fourth plan implemented 1986, also shown in Figure 3, the 'Suburban Development Area' of which is almost identical to that first designated in 1968. The major element distinguishing the second, third and fourth plans is the steady expansion of the Urban Development Areas, to the point that virtually all of the Kanto Plain outside the Suburban Development Area is now so designated.

Because the NCRDP were not accompanied by strong restrictions on development in areas such as the initially proposed greenbelt, and because virtually the whole Kanto plain is now designated either Existing Built-up Area, Suburban Development Area, or Urban Development Area, one should not expect to see a tidy pattern of mother-city/satellite-town development with green spaces in between such as that achieved around London. Rather, the plans should simply be understood as giving official status to the desire to disperse economic development from the 'over-congested' core to the outer edges of the region. Instead, planners have increasingly focused on encouraging a 'multi-nodal' metropolitan structure.

Since the early 1970s the idea of a 'multi-polar urban structure' has consistently held central place in plans to solve Tokyo's continuing problems of over-concentration in the CBD. Tokyo was experiencing skyrocketing land prices, worsening problems of congestion in the centre, overcrowding of transportation infrastructure, and further development in many central areas was limited by infrastructure shortfalls. It was hoped that the subcentres would provide a solution to the excessive development pressures on the centre and the growing physical size of the capital by drawing development away from the old CBD (see e.g. Kawakami, 1986; Japan National Land Agency, 1987; Tokyo Metropolitan Government, 1987, 1991; Tsuboi, 1992; Cybriwsky, 1998). In the early 1970s a plan put forward by the administration of Tokyo Governor Minobe proposed a bipolar metropolis with a new central business district based on Hachioji, Tachikawa and Tama New Town far to the west of the old CBD, that would relieve the overcrowding in central Tokyo. ${ }^{3}$ This proposal gradually evolved into the 'multi-polar metropolis' ideas of the 'My Town Tokyo' plan of 1980 and the Third Tokyo Long-Term Plan published in 1991, each during the long reign of Governor Suzuki Shunichi (see Figure 4). The publication 'Planning 


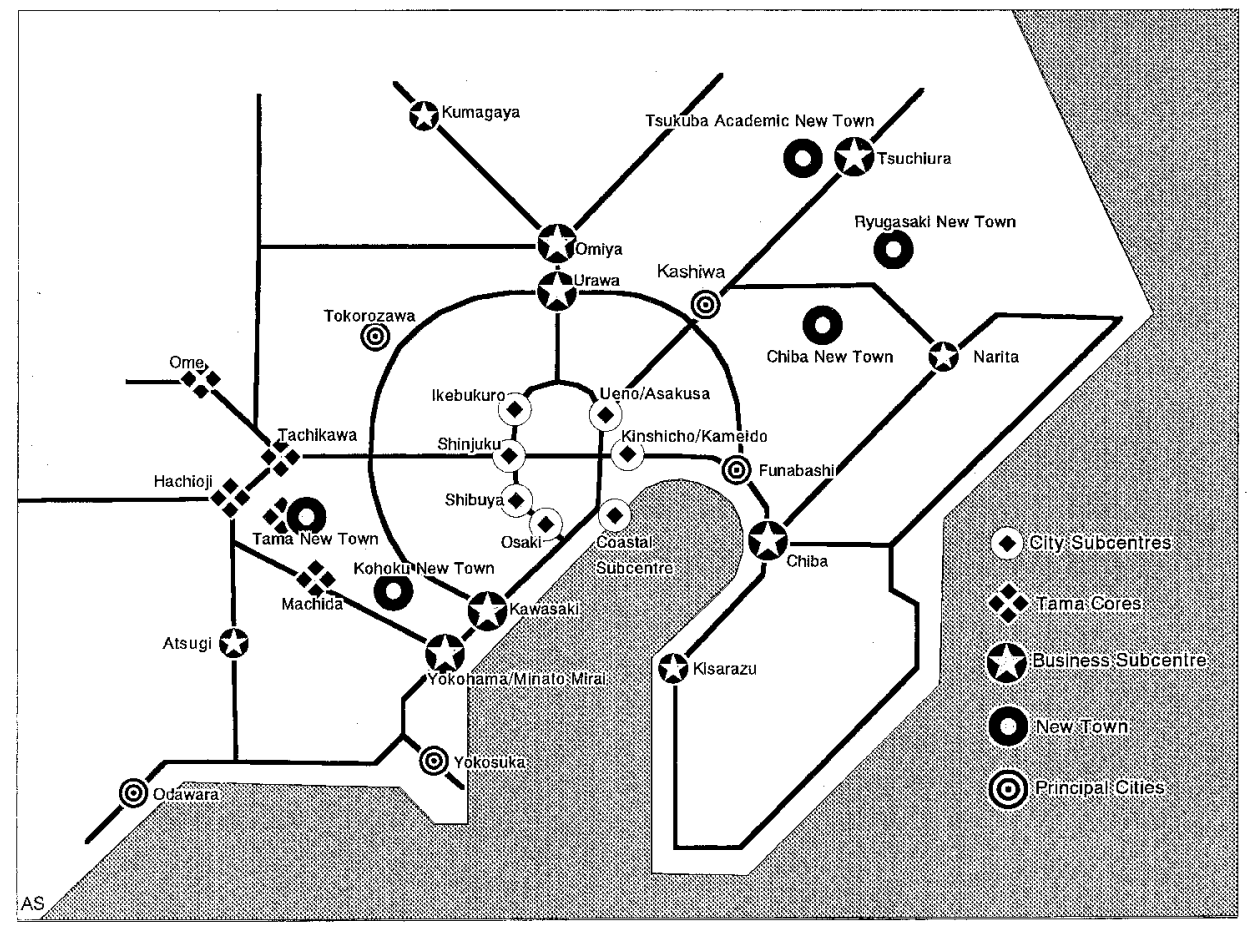

Figure 4. Third long-term plan for the Tokyo Metropolis, 1991. Source: Tokyo Metropolitan Government, 1991.

of Tokyo 1992' outlines the goals of the 'multi-centre city': "to make Tokyo into a city with a good balance between work and living, the dispersal of functions throughout the Tokyo Metropolitan Region will be promoted, and the structure of Tokyo will be changed from the present overly concentrated center to a multipolar structure" (Tokyo Metropolitan Government City Planning Bureau, 1992, p. 13). A large number of new subcentres were designated throughout the metropolitan region in these and later plans.

Subcentres and satellites also play an important role in the fundamental restructuring of the TMR urban structure proposed in the Fourth Comprehensive National Development Plan (CNDP) of 1986, and retained in the current Fifth CNDP of 1999. The basic concept proposed is that Tokyo should be ringed by three major new 'Business Core Cities' at Urawa/Omiya in Saitama prefecture, Makuhari/Chiba in Chiba prefecture, Kawasaki/Yokohama in Kanagawa prefecture, plus Tsukuba New Town in Ibaraki prefecture as a high-tech research centre. These would be developed as major employment and services subcentres in order to draw development pressure away from central Tokyo and create a multinucleated metropolitan structure (Japan National Land Agency, 1987, p. 124).

Although the Tokyo Metropolitan government has continued to strongly promote development in the Yamanote loop subcentres, many commentators suggest that this may exacerbate the problem of over-concentration rather than 
alleviate it. For example, in recent research on the capacity of central Tokyo to handle further growth of business functions, Onishi (1994) concludes that as its infrastructure is already far over stressed, and the marginal cost of expanding capacity in central Tokyo keeps increasing, further development of the Yamanote loop subcentres will merely add to problems of congestion in the centre. He suggests that the best policy will be to promote dispersal of business functions to the other business cores in the Kanto region, as proposed by the 4th CNDP. Tanaka (1990) similarly argues that because of their rapid growth, Tokyo's main subcentres along the Yamanote line have in effect coalesced into one giant CBD thus losing any positive role in relieving the congestion of the central area.

Two points should be made in summary of this necessarily brief review of the evolution of plans for the Tokyo region. First, a persistent feature of those plans since the early 1930s has been the concept of a polynuclear metropolitan structure. This initially took the form of promoting the development of the Yamanote ring subcentres such as Shinjuku, Shibuya and Ikebukuro, shifted in the 1960s to the idea of promoting satellite cities far from the metropolitan core while restricting development in the central areas, and has settled since the early 1970 s into the present pattern of promoting the development of a wide range of subcentres and satellites throughout the metropolitan region. These include the Yamanote ring subcentres, the Tama area 'cores', the 'business cores' of OmiyaUrawa, Kawasaki-Yokohama, and Chiba, and a variety of new towns and existing principal cities. The reasoning behind the 'multi-centre city' approach has since the early 1970s consistently been to reduce the strains on central area infrastructure and decrease the distance between home and work by promoting the creation of employment centres outside the $23 \mathrm{ku}$ area. Second, there has been an important shift in the measures proposed to carry such plans forward. While the plans from the 1930s to the late 1960s proposed a greenbelt that would require a strong regulatory regime to enforce it, since the collapse of the greenbelt in the 1960s the approach has shifted to one of encouraging growth points through their planning designation and the provision of transport infrastructure and public facilities. Projects such as Minato Mirai in Yokohama, and Makuhari Messe in Chiba and the new Tokyo coastal subcentre are major recent examples of this style of subcentre development. It is fair to say that since the failure of the greenbelt in the 1960s, the main efforts at metropolitan structure planning have been in encouraging new growth points rather than in restricting development in green areas. This approach has meant that to a considerable extent, the Kanto plain has become a vast continuously built up area, and growth points originally designated as satellites are now in fact subcentres within a large metropolitan region. Japanese planners have thus used their great expertise in public transport provision and urban infrastructure development to compensate for the continuing weakness of the Japanese land use planning system in attempts to structure metropolitan growth. ${ }^{4}$ The next section examines what measurable effects their efforts may have had on patterns of growth in the Tokyo Metropolitan Region.

\section{Subcentres and Metropolitan Growth, Empirical Evidence}

The analysis below focuses on the period from 1970 to 1995, as it was in the late 1960s that the greenbelt concept was abandoned, and it is since the early 1970s that the current generation of plans to promote multi-centred growth 
have been formulated, while 1995 is the most recent census available. Although the number of designated centres has steadily grown since 1970 and most were not yet designated in 1970, 25 years provides a suitably long period over which to examine changing patterns of population and employment in the TMA.

The analysis of population and employment change in the metropolitan region uses municipal government units as a basic unit. Within the central core of Tokyo (roughly the area within $15 \mathrm{~km}$ from Tokyo Station) the divisions are the 23 Special Wards which each have their own elected mayor and city council, while in Yokohama to the south of Tokyo the divisions are by normal city wards without a mayor. All other units are independent local governments. ${ }^{5}$ While the fragmentation of local government units has been an important factor limiting the effectiveness of metropolitan region planning, as for example in the case of the greenbelt of the first NCRDP, it is a boon for analysis of the sort attempted here, as municipal units (cities towns and villages) are a basic unit of the national population census.

As has often been noted by urban geographers, there are several disadvantages to using municipal areas as an analytical unit. The most significant in the present case are that the areas vary considerably in size and in their rate of urbanization. The relatively small, intensely built up wards of central Tokyo are clearly very different from the often larger, much more sparsely populated municipalities 50 to $70 \mathrm{~km}$ from the metropolitan centre. The analysis below looks at population and employment change in the TMA in two different ways; change in population and employment density, and absolute change in population and employment. For several reasons, looking at the change in population density is a useful way to show population growth, as comparing absolute change in population serves to highlight the growth of cities with a large land area and downplay smaller centres that may be growing more rapidly, while analysing rates of change tends naturally to emphasize those areas with a small existing population base. Population density is also an important measure of urbanization in itself, particularly when discussing the formation of subcentres that can compete with the metropolitan CBD. The disadvantage with using changes in density as a measure is that municipal areas which include a large rural area will tend to be downplayed in favour of areas which are smaller and more fully built up, even if their absolute population change is the same. Absolute population and employment changes are thus also examined here as a way of correcting for some of these limitations in the data. A further problem with local government areas is that they do not necessarily fit the economic area of influence of the subcentres. The larger examples such as Shinjuku, Shibuya, Ikebukuro, or Chiba fit reasonably well, but others such as Osaki which is a small centre in the much larger Shinagawa ward, or the designated subcentre of Kinshicho/Kameido which is split between two wards fit less well. That said, the municipal areas do offer a reasonable unit of analysis for the purposes of this paper.

Before looking at the geographical patterns of population and employment change, it will be useful to compare briefly the aggregate changes of different types of municipal areas. As shown in Table 1, there was a total growth in employment in the TMA of 5.66 million jobs and 9.22 million in population from 1970 to 1995. The average growth in the number of jobs and population per municipality was 15512 and 25261 respectively. The core area of Tokyo saw 
Table 1. TMA employment and population change, core area, suburbs, and subcentres, 1970-1995

\begin{tabular}{|c|c|c|c|c|}
\hline & $\begin{array}{l}\text { Employment } \\
\text { change }\end{array}$ & $\begin{array}{c}\text { Average } \\
\text { employment } \\
\text { change }^{1}\end{array}$ & $\begin{array}{l}\text { Population } \\
\text { Change }\end{array}$ & $\begin{array}{c}\text { Average } \\
\text { Population }^{\text {Change }^{1}}\end{array}$ \\
\hline All municipal areas ${ }^{2}$ & 5661732 & 15511.6 & 9220453 & 25261.5 \\
\hline Tokyo core area ${ }^{3}$ & 998437 & 142633.9 & 504756 & -72108.0 \\
\hline $\begin{array}{l}\text { Rest of } 23 \text { ward area } \\
\text { (outside seven core wards) }\end{array}$ & 379064 & 23691.5 & 367809 & -22988.1 \\
\hline $\begin{array}{l}\text { Suburban municipalities } \\
\quad \text { (outside Tokyo ward area) }\end{array}$ & 4284231 & 12527.0 & 10093018 & 29511.7 \\
\hline All subcentres ${ }^{5}$ & 1953372 & 65112.4 & 2184117 & 72803.9 \\
\hline Suburban subcentres ${ }^{6}$ & 1344047 & 58436.8 & 2704483 & 117586.2 \\
\hline
\end{tabular}

Source: Compiled by author from Population Census of Japan.

Notes: ${ }^{1}$ Average change per municipal area. ${ }^{2}$ All municipal areas in Tokyo, Kanagawa, Saitama, Chiba and Ibaraki prefectures, including the 23 wards of central Tokyo, and the 14 wards of Yokohama in 1970 totals 365 municipal areas. ${ }^{3}$ The seven core wards are Chuo, Chiyoda, Minato, Shinjuku, Bunkyo, Taito and Shibuya. ${ }^{4}$ Totalling 342 separate municipalities. ${ }^{5}$ The subcentres are all those shown in Figure 5, totalling 30. ${ }^{6}$ This group excludes the seven wards which include subcentres in the central 23 ward area of Tokyo, Shinjuku, Taito (Ueno/Asakusa), Sumida (Kinshicho), Koto (Kameido and Tokyo Coastal Subcentre), Shinagawa (Osaki), Shibuya, and Toshima (Ikebukuro).

growth of almost a million new jobs, averaging 142634 new jobs for each of the seven central wards, compared to only 23691 thousand for each of the rest of the central 23 wards, and 12527 for suburban municipalities outside the 23 ward area. The subcentres designated in the 3rd Long Term Plan shown in Figure 4 as a group show a considerably higher than average growth in employment at 65112 new jobs, and even if we exclude the seven subcentres in the 23 ward area of Tokyo (see Table 1, note 6), the subcentres still average 58437 new jobs. A rather different picture emerges in looking at population changes. While the population of the whole region increased by over 9 million, the seven core wards of Tokyo lost an average of 72108 each, and the suburban municipalities gained an average of 29512 , while subcentres as a whole gained an average of 72804 and the subcentres outside the 23 ward area averaged 117586 new residents. The 23 ward area of Tokyo clearly increased its dominance as an employment centre while losing large numbers of residents. Suburban areas outside the 23 wards also gained enormously both in employment and in population however, and to a significant degree, these gains seem to be particularly strong in the designated subcentres. While aggregated data such as that in Table 1 is useful to gain a general idea of the magnitude of differences between groups, it is misleading because it masks considerable differences within the groups. In particular there are significant variations among the 'suburban municipalities' and among subcentres related primarily to their geographic location in relation to central Tokyo. Those differences are examined in Figures 5 and 6.

Patterns of population change at the scale of the metropolitan region are indicated in Figure 5, which shows changes in population density in each municipality in the TMA during the period 1970 to 1995. A geographically corrected map showing the proposed multi-nodal structure of the 3rd Long-term 

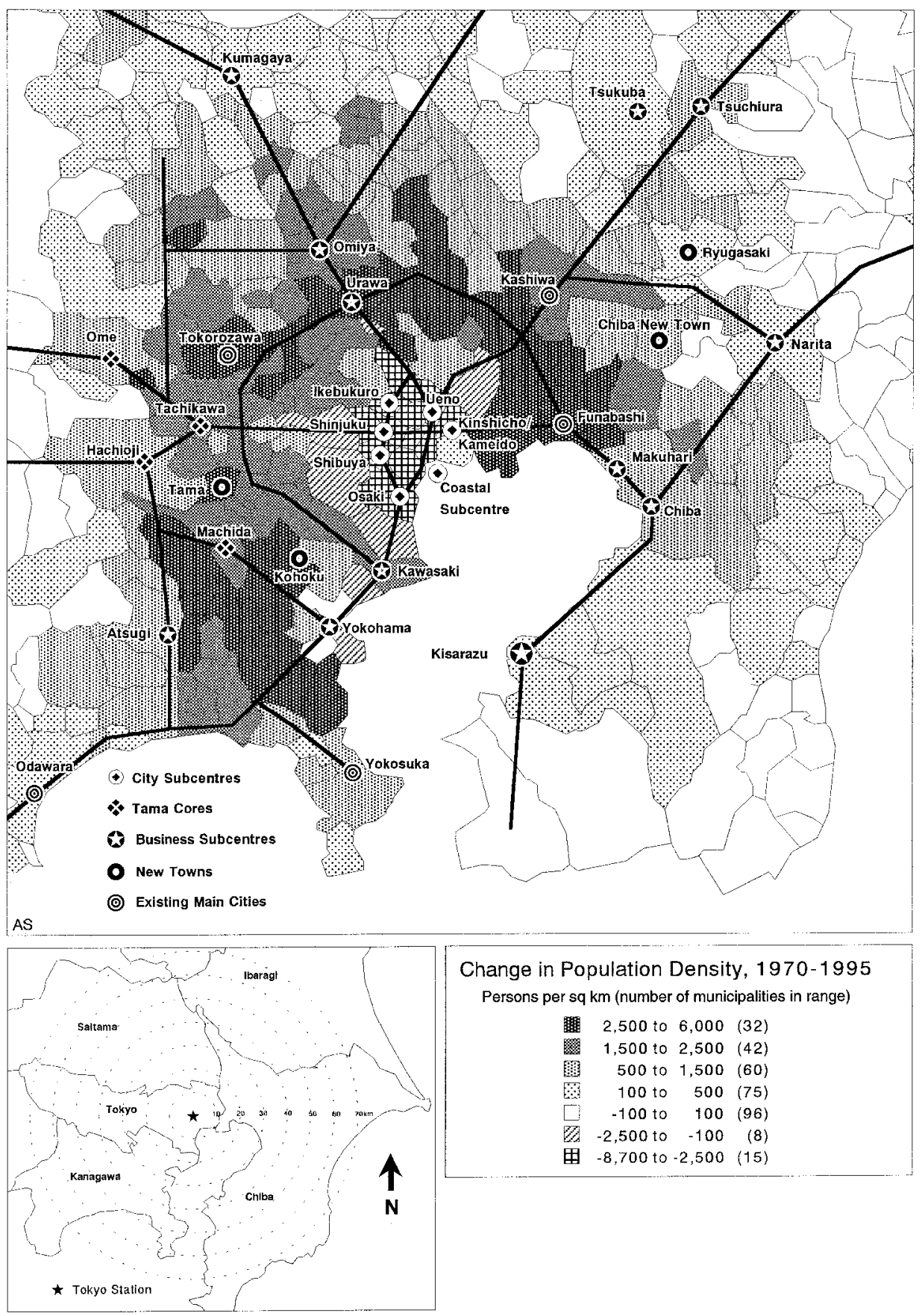

Figure 5. Change in population density, TMA 1970-95.

Plan for Tokyo of Figure 4 has been superimposed to show the relationship between population change and the designated subcentres. The dominant feature is the massive decentralization of population from the metropolitan core to the surrounding region. The 23 ward area saw a net loss of 872565 residents 
between 1970 and 1995, even though some of the 23 wards, such as Nerima and Itabashi in the north-west, and Adachi in the north-east, saw significant population gains. Net losses of population were also seen in the central wards of Yokohama, and would certainly also have been seen in the oldest parts of Kawasaki near Tokyo bay, but for the fact that Kawasaki is shown here as one unit because the 1970 census does not give separate population figures for its different wards, and population growth in the western parts of Kawasaki more than balance the losses in the east. The suburban areas surrounding these core areas of Tokyo, Kawasaki and Yokohama have, on the other hand, seen enormous increases in population, with a total increase of over 10 million between 1970 and 1995.

The decrease in population in the central areas within and around the Yamanote loop line is striking. This area includes all of the 'city subcentres' except the coastal subcentre which is primarily in Koto $\mathrm{ku}$ which has seen moderate growth. Just outside this central area of significant population loss is a second ring, comprising virtually all the rest of the central $23 \mathrm{ku}$ area which has either seen moderate population loss or small population gains. Outside this second ring is a third, broad belt which has seen the most intensive growth in population density, with increases of over 1500 persons $/ \mathrm{km}^{2}$ over 25 years. Stretching clockwise from the southern part of Yokohama in Kanagawa prefecture, through Tama and Tachikawa in western Tokyo, Tokorozawa and Urawa/Omiya in Saitama, to Kashiwa and Funabashi in Chiba, this belt is over $30 \mathrm{~km}$ in width at its widest in Kanagawa, and almost everywhere is over $20 \mathrm{~km}$ wide. The two arcs of highest population growth of over 2500 per $\mathrm{km}^{2}$ are seen to the south in the mid-part of Kanagawa prefecture, and in the north from Tokorozawa along the outer belt railway line to Funabashi.

The defining features of population change in the Tokyo region are thus the deconcentration of population from the central area within and immediately around the Yamanote loop line, and the increase of population in a broad band of between 20 to $40 \mathrm{~km}$ from Tokyo station. The ring of highest growth is broken only by the areas in the western suburbs of Tokyo around Tachikawa which had already substantially developed during the 1960s because of their high level of accessibility to the centre along the main east-west Chuo rail line. Significant population growth has also occurred throughout the rest of the Kanto plain, decreasing gradually with distance from the centre, and held at about $50 \mathrm{~km}$ from the centre in the west by the north-south line of mountains at Ome and Hachioji, and extending in the north and east to about $70 \mathrm{~km}$ from the centre.

The weak correlation between designated subcentres and the areas of greatest population growth is conspicuous. Only the three subcentres in the northern arc, Tokorozawa, Urawa and Funabashi, and Tama new town and Kohoku new town towards the south west are located in areas that saw the most rapid increase in population density. It seems fair to say that this was a result more of their location in the ring of high growth 25 to $35 \mathrm{~km}$ from Tokyo station, rather than their designation as subcentres. The possible exception to this are Tama and Kohoku new towns, which almost certainly saw higher levels of population increase than might otherwise have been the case because of the enormous quantities of housing built in them by both the public and private sectors over the last 25 years. Other subcentres such as Machida, Atsugi, Hachioji, Ome, Chiba, Ryugasaki and Tsukuba are not apparently gaining from their designated status, although it is reasonable to expect that they will see 
faster growth in future as the ring of fastest growth expands. Is seems fair to conclude that rapid suburban population growth has resulted in a relatively over-all pattern of population growth outside the core area and declining gradually outside a ring of peak growth located about $25 \mathrm{~km}$ from Tokyo Station. The area of highest population growth corresponds closely with the greenbelt of the 1958 NCRDP.

From the point of view of developing a strong multi-centred metropolitan structure, however, the pattern of employment growth is even more important than population growth. According to the advocates of 'concentrated deconcentration' or 'multi-nodal development' population decentralization need not result in longer travel times or distances, or increased volumes of commuter travel from suburbs to centre if nodes of employment are created in the suburban areas that can provide employment opportunities for those living near by. The pattern of employment change is therefore the key variable to understand the effects of decentralization.

Changes in the number of jobs per $\mathrm{km}^{2}$ between 1970 and 1995 are shown in Figure 6. As with Figure 5, measuring changes in density is effective in showing areas of significant growth while eliminating the arbitrary element of differences in size between municipalities. Such an approach does, however, tend to downplay the importance of cities such as Chiba which include a relatively large area of undeveloped land within their boundaries. That limitation notwithstanding, several aspects of the changing employment location patterns in the Tokyo Metropolitan Area are apparent here. First, the central area of Tokyo has seen by far the strongest growth of jobs of any area in the region, totalling over a million jobs during the 25-year period. The old industrial area just to the north of this central core, including Sumida, Katsushika, Arakawa, and Kita wards has seen the loss of over 100000 jobs during the same period. Older industrial areas in central Yokohama have seen similar declines in total employment.

As with patterns of population dispersal, there has been a broad band around the central area that has seen very large increases in employment density. Extending from Funabashi in the east, to Omiya/Urawa in the north, Tachikawa and Tama in western Tokyo and including most of the central part of Kanagawa prefecture, there is a wide belt of increased job intensity extending from about $20 \mathrm{~km}$ to $30 \mathrm{~km}$ from Tokyo station, and up to $50 \mathrm{~km}$ in Kanagawa. In contrast to patterns of population dispersal, however, several subcentres appear to have seen relatively higher levels of employment increase, including Funabashi, Kashiwa, Omiya/Urawa, Tachikawa, Tama, Kohoku, and Atsugi. Even Narita and Tsukuba/Tsuchiura, while seeing lower levels of increase than areas closer to the centre, have nonetheless seen higher rates of increase than other municipalities around them. This does not of course necessarily mean that designation as a subcentre is the reason that these centres are attracting jobs, as most of the strongest employment subcentres were so designated, and they may very well have seen a similar pattern of growth without designation. It does seem, though, that to a certain degree a polycentric pattern of development is occurring in the TMA. That said, there are also large areas of increased employment intensity outside the designated subcentres. The belt to the north and west of Funabashi, for example, the strips to the west of Ikebukuro and Shibuya, and the whole central area of Kanagawa prefecture, all show significant gains in employment that is not centred on a designated subcentre.

This point is further underlined by Figure 7, which plots the absolute change 

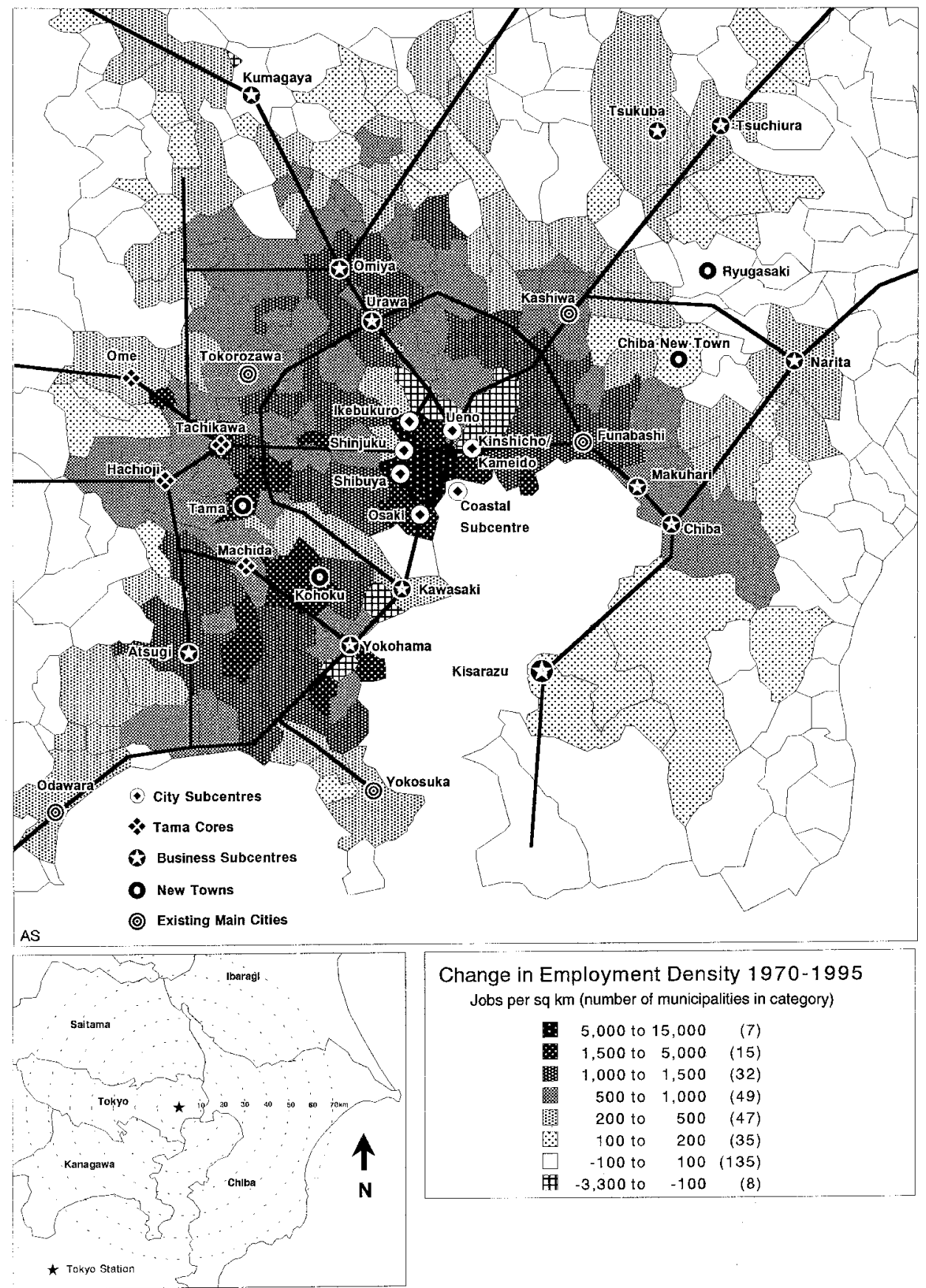

Change in Employment Density 1970-1995

Jobs per sq km (number of municipalities in category)

$\begin{array}{rrrr}5,000 \text { to } & 15,000 & (7) \\ 1,500 \text { to } & 5,000 & (15) \\ 1,000 \text { to } & 1,500 & (32) \\ 500 \text { to } & 1,000 & (49) \\ & 200 \text { to } & 500 & (47) \\ & 100 \text { to } & 200 & (35) \\ \square & -100 \text { to } & 100 & (135) \\ \square & -3,300 \text { to } & -100 & (8)\end{array}$

Figure 6. Change in employment density, Tokyo metropolitan area 1970-95.

in numbers employed against absolute change in population for all municipalities in the TMA. Subcentres are indicated with the same symbol used in Figures 5 and 6 , while other, non-designated, municipalities are indicated with a diamond. 


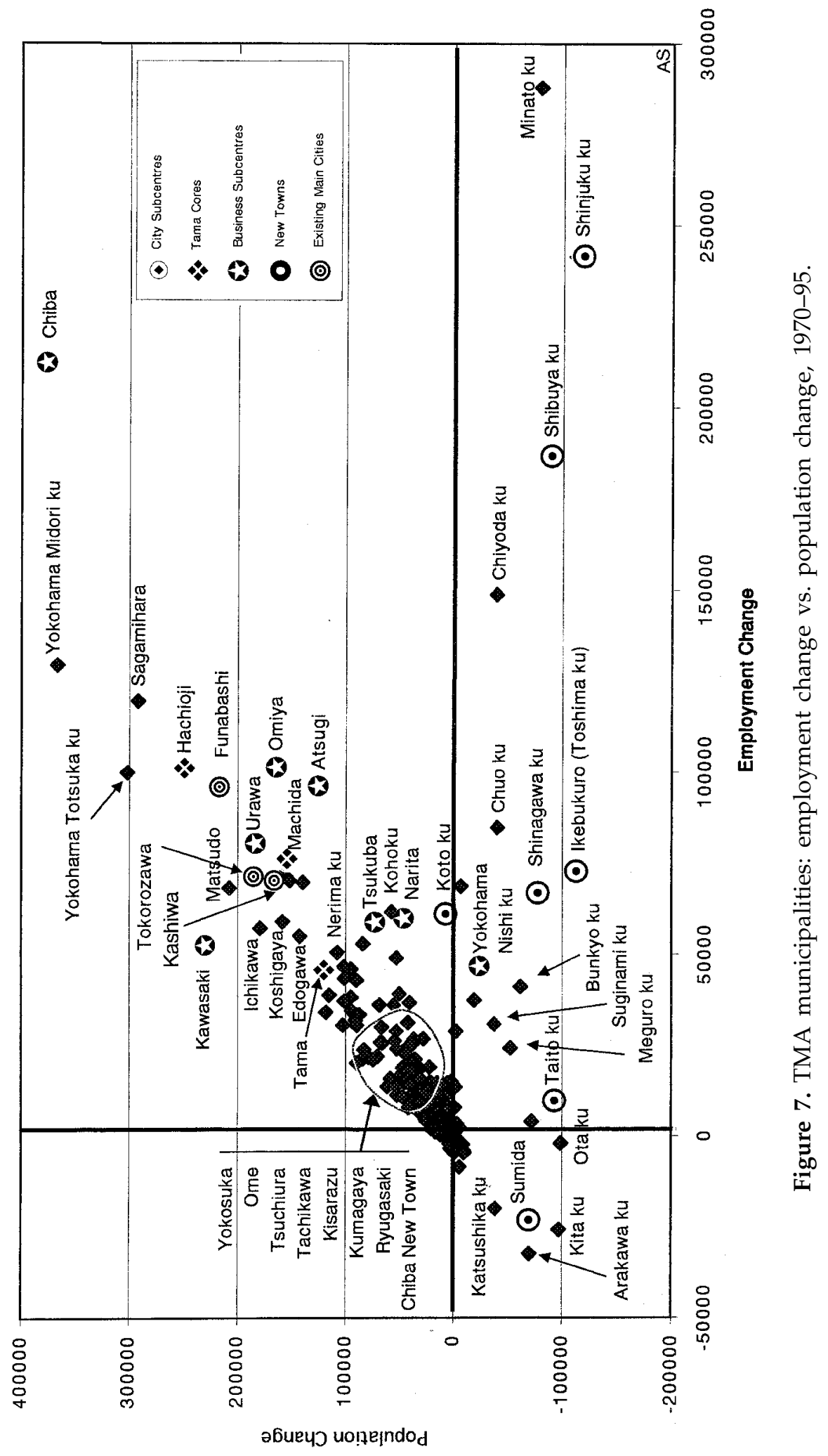


All the designated subcentres are also named, as are many of the other municipalities which show exceptional patterns of population and employment change.

It is possible to divide the municipalities shown in Figure 7 into four main groups. First are those in the bottom right of the plot which have seen significant employment gains at the same time as losing population. These are all wards in central Tokyo and Yokohama, some of which are designated subcentres such as Shinjuku, Shibuya and Ikebukuro, and others are the old CBD such as Chuo ku, Minato $\mathrm{ku}$ and Chiyoda ku. A second group is that in the lower left, which have lost both jobs and population. These are the old industrial wards of north-east Tokyo, only one of which (Sumida) includes a designated subcentre (Kinshicho). A third group is the dense cluster at the intersection and on the positive side of the two axes which includes the majority of the municipalities in the region. These show moderate growth of both population and employment, up to about 100000 of population and 50000 of employment. Defining the outer limit of this group are five designated subcentres, Tama new town, Tsukuba new town, Kohoku new town, Narita and Tokyo's Koto ku which includes both the Coastal city subcentre and part of Kinshicho Kameido city subcentre. A fourth group is then the remaining municipalities that saw exceptional growth of both employment and population. Of this fourth group, 10 are designated subcentres, and nine are not.

It seems fair to conclude from Figure 7 that while a number of subcentres have clearly grown at much higher rates than the average municipality in the TMA, many other designated subcentres have seen growth rather similar to that of other municipalities not so designated. More important than subcentre designation in shaping patterns of employment and population change seems to be the geographic location of the area. Municipalities in the central area of Tokyo share common patterns of change, as do those in the north-east of Tokyo, and those in the broad band of high growth just outside the 23 ward area. In each of these areas there are municipalities that were not designated which share characteristic patterns of change with designated subcentres. This suggests that the impact of planning designation may not be very strong. It also reflects the pattern seen in Figures 5 and 6 of rather large areas between the designated subcentres that were seeing significant population and employment growth.

It seems likely that this weak correlation between subcentre designation and population and employment change is primarily a result of two factors. First, the land use planning system has proven ineffective in either controlling the location of new development or even of ensuring that it is provided with main services. A wide variety of loopholes have allowed the continuation of scattered, haphazard development throughout the region. Even in Urbanization Control Areas, which are the most strictly regulated, exemptions are allowed for large-scale developments of over 20 hectares, and for all public projects such as roads, police stations, and schools (Hebbert \& Nakai, 1988a). This has resulted in rather dispersed patterns of development wherever land is available (see Hebbert, 1994; Sorensen, 1999; Sorensen, 2000a). Second, at the same time that it is virtually impossible to prevent development anywhere, neither have determined efforts been made to restrict investment to the designated subcentres. Both public and private investment has been widely dispersed throughout the region, and major new road and public transit projects seem just as likely to promote continued dispersed development as they are to focus it on certain centres. This 
suggests that alongside the designation and promotion of subcentres, some means of restricting development in non designated areas is necessary if a strongly polycentric structure is desired.

\section{Conclusions}

It seems fair to conclude that the Tokyo region is developing a polycentric employment structure. Although the Tokyo Metropolitan Area has seen enormous growth of jobs in the seven-ward core area of Tokyo (almost 1 million jobs) during the last 25 years, the great majority of job growth (over 4 million jobs) has been located in suburban areas outside the 23 ward area of Tokyo. Further, while only about one-third of the suburban job growth is located in designated suburban subcentres, those subcentres show almost four times the rate of growth of all suburban municipalities. It is not clear that this outcome is a result of planning policy, however, as a significant number of other centres are growing at the same rate as the most successful designated subcentres, and many of the designated subcentres show only moderate growth. This is an interesting finding, but we should not let it distract us from the possibly more important finding that the Tokyo region does seem to be developing a polycentric structure. There are many subcentres in the region, some designated and others not, which are showing strong growth of both jobs and of population. Some of these centres are located a considerable distance from the old central area and may have profound long-term impacts on the urban structure. Population growth has been much more evenly spread throughout the region, with the result that the metropolitan area is in the process of becoming a vast continuously built up urban area. Further research is clearly required on how this emerging polycentric structure is affecting living, working and travel patterns in the region.

It is also worth noting that the hoped-for benefits of polycentric development may be mitigated in the Tokyo case by the continuing strong growth of the central area, which has seen an increase of almost a million jobs in the past 25 years and is still the dominant employment centre. According to travel surveys commuting times in the Tokyo region have been getting steadily longer, increasing from an average commute (one-way) of 61 minutes in 1975 to 64 minutes in 1985 (Uchida, 1991, p. 7), and during the same period the share of commuters travelling between 1.5 to 2 hours one-way increased from $12.5 \%$ to $14.9 \%$. According to Okamoto $(1997$, p. 86) the average one-way commuting time had increased to 80 minutes in 1990. Much of the increase in average commuting times seen over the last 25 years appears to be a result of the ever-increasing employment in the centre, which does appear from the patterns of employment growth seen in Figure 6 to have developed into one vast CBD within the Yamanote line which now includes the 'subcentres' of Shinjuku, Shibuya and Ikebukuro, as Onishi (1994) and Tanaka (1990) have suggested. It would be interesting to know whether the growth of employment in subcentres has served to mitigate the increase in average commuting times, or exacerbate it. Answering that question will require further research on the patterns of travel to the different subcentres. Are they allowing a larger share of workers who reside in the suburbs to travel short distances to work in a nearby suburban employment centre, or are significant numbers of workers travelling even farther to such centres? 
One of the main reasons for promoting the development of a polycentric urban structure is to enable shorter work travel trips and high levels of public transit use. While Tokyo is a transit metropolis par excellence (see Cervero, 1998), dispersed patterns of development seem likely to gradually undermine the high levels of transit use now still prevailing. Dispersed population and employment growth in the outer urban area is creating a more car-dependent metropolitan area, and much of the enormous growth of road use is in the outer areas of the metropolitan region rather than in the core areas (Ohta, 1994). A second question for further research is thus how the growth of suburban employment is affecting modal split between public transit and the private automobile.

From the evidence examined here it seems that Japan's pragmatic approach to metropolitan structure planning, designating numerous subcentres and effectively abandoning attempts to restrict development elsewhere, has had profound consequences. Although prominent subcentres are developing, there are also broad areas in the band of $20-40 \mathrm{~km}$ from Tokyo station that have seen enormous growth of both jobs and population. It seems clear that the old idea of preserving significant blocks of undeveloped green land within the metropolitan area is no longer an option in the Tokyo region. Whether the developing polycentrism of the region can successfully provide the hoped-for benefits of the old satellite/subcentre schemes without such breaks in the urban fabric is as yet unclear, but for the residents of the Tokyo metropolitan region the lost opportunity to preserve some significant green areas within the built up area seems likely to be a long-term quality of life issue. This grand experiment in virtually unbroken metropolitan development over an area of some $15000 \mathrm{~km}^{2}$ seems certain to hold valuable lessons for urban development elsewhere, particularly for other developing mega-urban regions in Asia such as Bangkok, Jabotabek or Shanghai where the sort of regulatory regimes necessary to enforce greenbelts or other breaks in the metropolitan fabric seem as unlikely to develop as they have been in Japan.

\section{Notes}

1. This discussion of the development of the Tokyo rail system is based on Arisue \& Aoki (1970), Yamamoto (1993) and Ericson (1996).

2. The term used is kōgyo which refers to manufacturing industry, rather than to business in general.

3. The location of the proposed new CBD in the western suburbs of Tokyo prefecture instead of at other prominent existing employment centres such as Yokohama, Chiba or Omiya/Urawa is no accident, and reflects the long standing unwillingness of the Tokyo government to promote decentralization models that would move any of its valuable commercial tax base to other nearby prefectures. The incorporation of subcentres in other prefectures into official Tokyo Prefecture documents such as the Third Long-term Plan shown in Figure 4 is thus a significant shift of policy. It seems likely that the enormous growth of jobs in Tokyo's old CBD during the 1980s may have aided this change of policy, as it became clear that central Tokyo was still the unchallenged business location, and that if central area congestion was to be reduced, a range of subcentres would have to be endorsed.

4. Although the Japanese land use planning and development control system was thoroughly revised in 1968 with the explicit goal of preventing urban sprawl by focusing development in Urbanization Promotion Areas (UPA) and preventing development in Urbanization Control Areas (UCA), numerous loopholes rendered the system ineffective, and haphazard unserviced sprawl has continued in both UPA and UCA areas (for a more detailed analysis of the impacts of UPA/UCA zoning, see Hebbert \& Nakai, 1988b; Hebbert, 1994; Sorensen, 1999, 2000a). 
5. In cases where the geographical unit changed since 1970, such as in several of Yokohama's wards $(\mathrm{ku})$ where the larger peripheral wards have been repeatedly subdivided, the original boundaries have been maintained and data aggregated accordingly. In the five prefectures of Tokyo, Kanagawa, Saitama, Chiba and Ibaraki this gives a total of 365 local units.

\section{References}

Alden, J.D. (1984) Metropolitan planning in Japan, Town Planning Review, 55(1), pp. 55-74.

Arisue, T. \& Aoki, E. (1970) The development of railway network in the Tokyo region from the point of view of the metropolitan growth, in: Japanese Cities: A Geographical Approach (Tokyo: Association of Japanese Geographers).

Barton, H. (1992) City transport: strategies for sustainability, in: M.J. Breheny (Ed.) Sustainable Development and Urban Form (London: Pion).

Blumenfeld, H. (1967) The Modern Metropolis (Boston, MA: MIT Press).

Breheny, M.J. (1995) Counter-urbanisation and sustainable urban forms, in: J. Brotchie, M. Batty, E. Blakely, P. Hall \& P. Newton (Eds) Cities in Competition: Productive and Sustainable Cities for the 21st Century (Melbourne: Longman).

Breheny, M.J. \& Rookwood, R. (1993) Planning the sustainable city region, in: A. Blowers (Ed.) Planning for a Sustainable Environment, pp. 150-189 (London: Earthscan).

Cervero, R. (1989) America's Suburban Centers: The Land Use-Transportation Link (Boston: Unwin Hyman).

Cervero, R. (1998) The Transit Metropolis: A Global Inquiry (Washington DC: Island Press).

Cervero, R. \& Wu, K.-L. (1997) Polycentrism, commuting, and residential location in the San Francisco Bay area, Environment and Planning A, 29, pp. 865-886.

Cherry, G.E. (1982) The Politics of Town Planning (Harlow: Longman).

Cherry, G.E. (1988) Cities and Plans (London: Edward Arnold).

Commission of the European Communities (CEC) (1990) Green Paper on the Urban Environment (Brussels: Commission of the European Communities).

Cybriwsky, R. (1998) Tokyo: The Changing Profile of an Urban Giant (Chichester, New York, Weinheim, Brisbane, Singapore, Toronto: John Wiley \& Sons).

Elkin, T., McLaren, D. \& Hillman, M. (1991) Reviving the City: Towards Sustainable Urban Development (London: Friends of the Earth).

Ericson, S.J. (1996) The Sound of the Whistle: Railroads and the State in Meiji Japan (Cambridge, MA: Council on East Asian Studies Harvard University).

Fowler, E.P. (1992) Building Cities that Work (Montreal: McGill-Queen's University Press).

Gordon, P. \& Richardson, H.W. (1990) Gasoline consumption and cities, a reply, Journal of the American Planning Association, 55, pp. 342-345.

Gordon, P. \& Richardson, H.W. (1995) Sustainable congestion, in: J. Brotchie, M. Batty, E. Blakely, P. Hall \& P. Newton Cities in Competition: Productive and Sustainable Cities for the 21st Century, pp. 348-358 (Melbourne: Longman).

Gordon, P., Richardson, H.W. \& Wong, H.L. (1986) The distribution of population and employment in a polycentric city: the case of Los Angeles, Environment and Planning A, 18, pp. 161-173.

Hall, P. (1997) The future of the metropolis and its form, Regional Studies, 31(3), pp. 211-220.

Hall, P., Gracey, H., Drewett, R. \& Thomas, R. (1973) The Containment of Urban England (London: Allen and Unwin).

Hanayama, Y. (1986) Land Markets and Land Policy in a Metropolitan Area: A Case Study of Tokyo (Boston: Oelgeschlager, Gunn and Hain).

Hebbert, M. (1994) Sen-biki amidst Desakota: urban sprawl and urban planning in Japan, in: I. Masser, P. Shapira \& D.W. Edgington (Eds) Planning for Cities and Regions in Japan, pp. 70-91 (Liverpool: Liverpool University Press).

Hebbert, M. \& Nakai, N. (1988a) Deregulation of Japanese planning, Town Planning Review, 59(4), pp. 383-395.

Hebbert, M. \& Nakai, N. (1988b) How Tokyo Grows (London: STICERD).

Honjo, M. (1978) Trends in development planning in Japan, in: F. Lo \& K. Salih Growth Pole Strategy and Regional Development Policy: Asian Experience and Alternative Approaches, pp. 3-23 (Oxford: Pergamon Press and UNCRD).

Howard, E. (1898, 1985) Garden Cities of Tomorrow (Rhosgoch, Wales: Attic Books).

Ishida, Y. (1987) The Last 100 years of Japanese Urban Planning Nihon Kindai Toshikeikaku no Hyakunen (Tokyo: Jichitai Kenkyusha). 
Ishizuka, H. \& Ishida, Y. (1988) Tokyo: Urban Growth and Planning 1868-1988 (Tokyo: Center for Urban Studies).

Japan National Land Agency (1987) The Fourth Comprehensive National Development Plan (Tokyo: National Land Agency Kokudocho).

Kawakami, H. (1986) Multi-center structure theory and urban renewal master plan of Tokyo, Journal of the Faculty of Engineering, The University of Tokyo (B), 38(4), pp. 111-128.

Kurosawa, T., Teraoku, J., Youn, T. \& Nakagawa, Y. (1996) The influence of the national capital region development plan in Saitama Prefecture [Saitama Ken ni okeru Shutoken Seibi Keikaku no Eikyo ni kansuru Kenkyu], Collected Papers of the Japanese City Planning Association [Nihon Toshi Keikaku Gakkai Ronbun Shu], 31, pp. 1-6.

McDonald, J.F. \& Prather, P. (1994) Suburban employment centers: the case of Chicago, Urban Studies, 31, pp. 201-218.

Mumford, L. (1940) The Culture of Cities (London: Secker and Warburg).

Newman, P. \& Kenworthy, J. (1989a) Gasoline consumption and cities. A comparison of US cities with a global survey, Journal of the American Planning Association, 55(1), pp. $24-37$.

Newman, P. \& Kenworthy, J. (1989b) Cities and Automobile Dependence: A Sourcebook (Aldershot: Brookfield VT, Gower).

Ohta, K. (1994) Transport problems and policies of the Tokyo metropolitan region, in: Contemporary Studies in Urban Environmental Management in Japan, pp. 106-127 (Tokyo, Dept. of Urban Engineering University of Tokyo, Kajima Institute Publishing).

Okamoto, K. (1997) Suburbanization of Tokyo and the daily lives of suburban people, in: P.P. Karan \& K. Stapleton The Japanese City, pp. 79-105 (Lexington, KY: The University Press of Kentucky).

Onishi, T. (1994) A capacity approach for sustainable urban development: an empirical study, Regional Studies, 28(1), pp. 39-51.

Owens, S.E. (1991) Energy Conscious Planning (London: Council for the Protection of Rural England).

Rickaby, P.A. (1987) Six settlement patterns compared, Environment and Planning B: Planning and Design, 14, pp. 193-223.

Saarinen, E. (1943) The City: its Growth, its Decay, its Future (Boston, MA: MIT Press).

Sassen, S. (1991) The Global City: New York, London, Tokyo (Princeton, NJ: Princeton University Press).

Self, P. (1961) Cities in Flood (London: Faber and Faber).

Sherlock, H. (1991) Cities are Good for Us (London, Paladin).

Sorensen, A. (1999) Land readjustment, urban planning and urban sprawl in the Tokyo metropolitan area, Urban Studies, 36(13), pp. 2333-2360.

Sorensen, A. (2000a) Land readjustment and metropolitan growth: an examination of land development and urban sprawl in the Tokyo metropolitan area, Progress in Planning, pp. 1-113.

Sorensen, A. (2000b) Conflict, consensus or consent: implications of Japanese land readjustment practice for developing countries, Habitat International, 24(1), pp. 51-73.

Tanaka, T. (1990) The analysis of the relationship between recent trends of office accumulation in Tokyo and floor-area control, Collected Papers of the Japanese City Planning Association Nihon Toshi Keikaku Gakkai Ronbun Shu, 25, pp. 439-444.

Tokyo Metropolitan Government (1987) Second Long-term Plan for the Tokyo Metropolis (Tokyo: Tokyo Metropolitan Government).

Tokyo Metropolitan Government (1989) Tokyo no Toshi Keikaku Hyaku Nen (One Hundred Years of Tokyo City Planning) (Tokyo: Tokyo Metropolitan Government).

Tokyo Metropolitan Government (1991) Third Long-term Plan for the Tokyo Metropolis (Tokyo: Tokyo Metropolitan Government).

Tokyo Metropolitan Government City Planning Bureau (1992) Planning of Tokyo 1992 (Tokyo: Tokyo Metropolitan Government).

Tsuboi, Y. (1992) Urban Fringe of Tokyo Metropolitan Area. Trends and Prospects of World Urbanization. Nihon University International Symposium (Tokyo: University Research Centre Nihon University).

Uchida, K. (1991) Current issues in Tokyo regional transport planning, Wheel Extended, 77(September), pp. 2-9.

Watanabe, S. (1980) Garden city, Japanese style: the case of Den-en Toshi Company Ltd. 1918-1928, in: G.E. Cherry Shaping an Urban World, pp. 129-144 (London: Mansell).

Yamamoto, H. (Ed.) (1993) Technological Innovation and the Development of Transportation in Japan (Tokyo: United Nations University Press). 